\title{
Exposure Assessment of Toxicologically Relevant Volatile Organic Compounds Emitted from Polymer-Based Costume Masks
}

\author{
Morgane Even,* Alexander Roloff,* Nils Lüttgert, Jonathan Beauchamp, Daniel Stalter, Agnes Schulte, \\ Christoph Hutzler, and Andreas Luch
}

Cite This: Chem. Res. Toxicol. 2021, 34, 132-143

Read Online

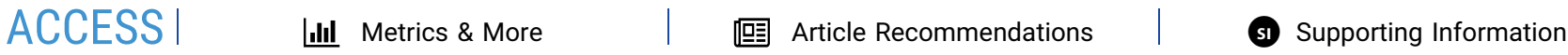

ABSTRACT: Plastic costume masks regularly exhibit unpleasant odors that may be associated with the emissions of volatile organic compounds (VOCs). Upon inhalation, VOCs might adversely affect the wearer's health if the exposure exceeds regulatory threshold values. The VOCs emitted from a selection of costume masks $(n=12)$ were characterized semiquantitatively with a screening method based on GC/MS measurements in dynamic headspace sampling mode. Furthermore, odors associated with the masks were evaluated by a sensory panel. Two masks emitted particularly high concentrations of ethylbenzene, xylenes, and cyclohexanone and exhibited the most intense and unpleasant odors, which were described as rubber-like, pungent, and leather-like.

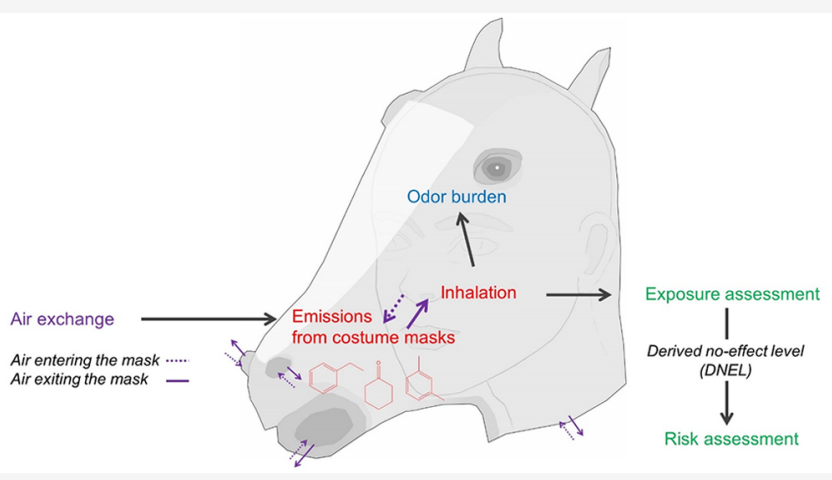
To simulate and assess the inhalation exposures for wearers of these masks, an innovative experimental setup based on a doll's head was developed, with sampling of emitted volatiles on adsorption material and subsequent analysis by thermal desorption-GC/MS. The measured inhalable concentrations of cyclohexanone exceeded the derived no-effect level (DNEL) for systemic effects on the general population over several hours of wearing, and also after repeated use. Importantly, the cyclohexanone DNEL was reevaluated in relation to a recent study on inhalation toxicity in rodents and was found to be significantly lower $\left(1.4 \mathrm{mg} \cdot \mathrm{m}^{-3}\right)$ compared to the industry-derived values $(10-20$ $\mathrm{mg} \cdot \mathrm{m}^{-3}$ ), thus aggravating the health risks associated with inhalation exposure from some of the costume masks tested. Finally, a comparison of the inhalable concentrations derived from the simulated exposure assessments with those derived from measurements in miniaturized emission test chambers indicate that microchambers represent a useful tool for high-throughput analysis. The influences of temperature and inhalation/exhalation flow rates on VOC exposures were also studied.

\section{INTRODUCTION}

Plastics may contain different chemical additives and impurities that can migrate into and contaminate food, water, soil, and air. ${ }^{1}$ Among others, volatile organic compounds (VOCs) in plastic-based materials can be released into the air at ambient temperature on account of their high vapor pressures. If inhaled, some of these compounds potentially elicit adverse health effects. It has recently been demonstrated, for example, that a mixture of aromatic compounds, namely benzene, toluene, ethylbenzene, and $p$-xylene, can disturb the functions of pulmonary surfactants. ${ }^{2}$ In another study, the polycyclic aromatic hydrocarbon (PAH) naphthalene was shown to cause acute airway cytotoxicity following inhalation by mice. ${ }^{3}$ Other VOCs, such as acetophenone and isophorone, were characterized as local irritants as they stimulated responses in trigeminal neurons in mice. ${ }^{4}$

Emissions of VOCs from polymer-based consumer products, including children's toys, have been studied and quantified in recent years. ${ }^{5,6}$ Specialized laboratory equipment, such as emission test chambers, allows samples to be characterized under conditions that mimic indoor environments, and this has recently facilitated realistic inhalation exposure assessments of toys. $^{7-10}$ For certain products such as costume masks, however, which are frequently worn during Halloween, cultural carnivals, or other themed parties, very little is known about the wearer's exposure to their constituent VOCs. This deficit is a direct consequence of the complex exposure scenario: while wearing a mask, the emissions source (the mask) and the site(s) of inhalation (nose and/or mouth) are in close proximity and within an almost entirely enclosed space of low volume. The air exchange here is actively driven by the inhalation/exhalation pattern of the wearer, as opposed to a passive exchange with ambient air (see the abstract graphic for

Received: September 25, 2020

Published: January 5, 2021 
an exposure schematic). Concentrations derived from measurements in conventional emission test chambers are therefore not expected to be representative of actual exposure.

Previous work has raised concerns about the potential release of VOCs from costume masks. A quantitative analysis commissioned by a German magazine detected the presence of benzene, toluene, xylene, phenol, and cyclohexanone in various specimens, but no emissions measurements were carried out to assess the actual inhalation exposure. ${ }^{11}$ Indeed, a systematic screening of the market for products exhibiting potentially hazardous VOC emissions by official control authorities would be desirable but is currently out of reach due to the lack of harmonized analytical methods that combine accurate emissions measurements with a reasonable sample throughput. As a precautionary measure, the German Federal Office of Consumer Protection and Food Safety (BVL) advises consumers to self-check purchased costume masks by assessing how easy it is to breathe when wearing the mask while dancing in a crowded room, and recommends avoiding masks with unpleasant odors. ${ }^{12}$

Indeed, the release of VOCs from consumer products may be accompanied by unpleasant odors that can be associated with symptoms of headache and nausea upon extended exposure. Several studies identified off-odorants in toys using a combination of sensory evaluations by trained panels and gas chromatography coupled to an olfactory detector (GC/O). In such tests, however, while the panel evaluations are typically carried out at ambient conditions, instrumental analysis of odor components usually requires sample extraction. This is commonly achieved at relatively high temperature, e.g., either via solvent-assisted flavor evaporation (SAFE) $)^{13-13}$ or by thermal extraction. ${ }^{16}$ Since sample extraction techniques are typically performed on the sample as a whole, subsequent analyses cannot distinguish between odorous VOCs that are emitted from the surface and those that are enclosed within the polymeric matrix and may not be released into the gas phase under conditions of normal use.

Correlations between odors and VOC emissions have been found in studies on building materials, ${ }^{17,18}$ automobile air condition evaporators (applying forced parameters, such as $100 \%$ relative humidity), ${ }^{19}$ and sewage sludge composting plants, ${ }^{20}$ among others. To the best of our knowledge, however, no data have been collected hitherto on the correlation between perceived odors and VOC emissions from plastic consumer products measured under realistic conditions (ambient temperature and humidity). Such knowledge is crucial when estimating human inhalation exposures to VOCs.

In this study, we investigated the correlation between sensory impressions and emission properties of polymer-based costume masks. First, a semiquantitative analysis of the emissions of VOCs was performed, allowing a quick preselection of samples with high VOC emissions. ${ }^{10}$ In parallel, sensory analyses were conducted to determine the odor attributes and intensities, together with the hedonic ratings of the samples. Furthermore, we describe an innovative setup based on a doll's head to simulate and assess realistic inhalation exposures while wearing costume masks. This system is inspired by a study on disposable filtering facepiece (FFP) respirators. ${ }^{21}$ Finally, we measured VOC emissions from mask sample pieces using a commercial microchamber device (a miniaturized emission test chamber) and compared these data with those obtained from the doll's head setup.

\section{MATERIALS AND METHODS}

2.1. Chemicals. Chemicals were supplied from Merck (Darmstadt, Germany), Sigma-Aldrich (Steinheim, Germany), and TCI Chemicals (Zwijndrecht, Belgium). Further details are reported in Table S1. Analytical grade ethyl acetate and dichloromethane were obtained from Merck and used as solvents. Nitrogen $\left(\mathrm{N}_{2}\right)$ and helium of purity $\geq 99.999 \%$ (5.0) from Linde (Pullach, Germany) were used. All chemicals, including solvents and standard solutions, were handled with appropriate care under a fume hood, minimizing contact to potentially harmful substances.

2.2. Samples and Polymer Characterization. Twelve costume masks were bought from local or online shops and kept in gastight, aluminum composite-layer film bags at room temperature until usage. Sample details are summarized in Table 1, and pictures of the samples are presented in Figure S1.

Table 1. Overview of 12 Costume Masks

\begin{tabular}{|c|c|c|c|}
\hline no. & name & source $^{a}$ & origin \\
\hline 1 & donkey & 1 & unknown \\
\hline 2 & panda & 1 & unknown \\
\hline 3 & sumo & 1 & unknown \\
\hline 4 & grandpa & 1 & China \\
\hline 5 & wolf & o & China \\
\hline 6 & dwarf 1 & o & unknown \\
\hline 7 & dwarf 2 & o & unknown \\
\hline 8 & rabbit & o & China \\
\hline $9 \mathrm{~A}, 9 \mathrm{~B}, 9 \mathrm{C}$ & horse & o & unknown \\
\hline $10 \mathrm{~A}, 10 \mathrm{~B}$ & unicorn & o & unknown \\
\hline 11 & zombie & o & China \\
\hline 12 & horror & o & China \\
\hline
\end{tabular}

Pyrolysis-GC/MS was used to identify the polymer type of each of the masks via thermal degradation according to the method detailed in our previous work. ${ }^{10} \mathrm{~A}$ Beilstein test was also carried out to confirm the presence of halogens: small pieces $\left(\sim 1 \mathrm{~mm}^{2}\right)$ were placed on a hot copper ring and heated in a flame, whereby a green flame color indicated the presence of halogens.

2.3. Conditioning of Thermal Desorption Tubes and Internal Standard Spiking. Glass thermal desorption (TD) tubes $(6.0 \times 0.4 \mathrm{~cm}$ i.d. $\times 0.6 \mathrm{~cm}$ o.d.) filled with Tenax TA (Gerstel $\mathrm{GmbH}$, Mülheim an der Ruhr, Germany) were used to capture VOCs emitted from individual samples. Prior to sampling, tubes were conditioned for $3 \mathrm{~h}$ with an $\mathrm{N}_{2}$ flow of ca. $75 \mathrm{~mL} \cdot \mathrm{min}^{-1}$ at $300{ }^{\circ} \mathrm{C}$. Cyclodecane dissolved in ethyl acetate was used as an internal standard on the tubes, either at $50 \mathrm{ng} \cdot \mu \mathrm{L}^{-1}$ for dynamic headspace (DHS) sampling or at $500 \mathrm{ng} \cdot \mu \mathrm{L}^{-1}$ for exposure simulation and microchamber experiments; solutions were stored in a freezer $(-18$ ${ }^{\circ} \mathrm{C}$ ) until use. A $1 \mu \mathrm{L}$ aliquot of internal standard solution was spiked onto the TD tubes by using a tube spiking system (Gerstel) equipped with a rinsed $10 \mu \mathrm{L}$ microvolume syringe. Afterward, the tubes were dried with $100 \mathrm{~mL}$ of $\mathrm{N}_{2}$ at a flow rate of $100 \mathrm{~mL} \cdot \mathrm{min}^{-1}$. The conditioned and internal standard spiked tubes were stored at room temperature in tight plastic storage containers (Gerstel) and subsequently loaded and analyzed within 3 days.

2.4. Dynamic Headspace Sampling and Score. First, a semiquantitative analysis of the emissions of VOCs from 12 masks was performed using DHS sampling coupled online to GC with mass spectrometric detection (GC/MS), as demonstrated in our previous work. ${ }^{10}$ Circular sample pieces with a diameter of $8 \mathrm{~mm}$ were punched manually from each of the 12 mask samples with a metal punching tool. Samples were placed in $20 \mathrm{~mL}$ glass headspace vials with the inner face of the mask pointing upward; the vials were then closed with magnetic caps fitted with silicon/polytetrafluoroethylene (PTFE) septa. After $60 \pm 5$ min equilibration at room temperature, the headspace was purged with $600 \mathrm{~mL}$ of $\mathrm{N}_{2}$ at a flow rate of $15 \mathrm{~mL}$. 


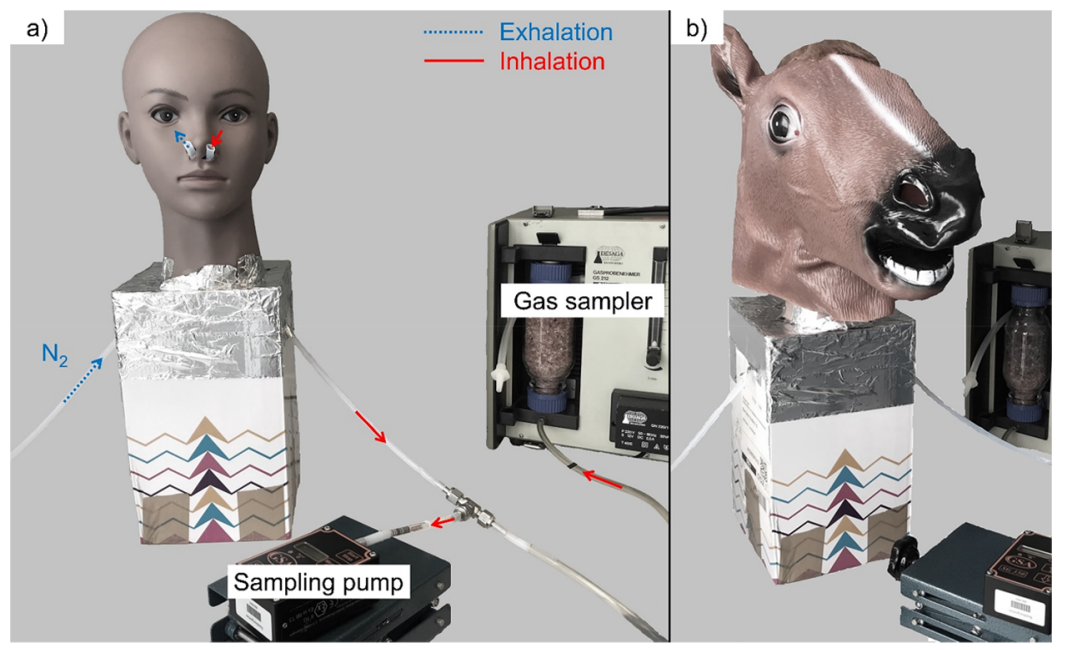

Figure 1. Experimental setup for evaluation of simulated exposure of volatiles associated with wearing a costume mask. The doll's head sampling system is shown without mask (a) and in action with sample 9B (b) (see Table 1).

$\min ^{-1}$. Analytes in the headspace were trapped at $23{ }^{\circ} \mathrm{C}$ on conditioned Tenax TA TD tubes spiked with internal standard (described in section 2.3). The transfer heater between the vial and the desorption tube was held at a constant temperature of $50{ }^{\circ} \mathrm{C}$. The DHS system was cleaned between each run: An empty glass vial was flushed with $1 \mathrm{~L}$ of $\mathrm{N}_{2}$ at a flow rate of $100 \mathrm{~mL} \cdot \mathrm{min}^{-1}$ at $70^{\circ} \mathrm{C}$ while simultaneously holding the transfer heater at $70{ }^{\circ} \mathrm{C}$. The analyteloaded TD tubes were analyzed by GC/MS as described in section 2.7 .

A "DHS score" was calculated for each target analyte and sample. The signal areas $\left(A_{\text {sample,analyte }}\right)$ were normalized to the internal standard signal area $\left(A_{\text {sample,IS }}\right)$ and corrected for the blank values ( $A_{\text {blank,analyte }}$ and $A_{\text {blank,IS }}$, respectively):

$$
\begin{aligned}
& \text { analyte-specific DHS score }=\frac{A_{\text {sample,analyte }}}{A_{\text {sample,IS }}}-\frac{A_{\text {blank,analyte }}}{A_{\text {blank,IS }}} \\
& \text { DHS sum score ( } n \text { analytes })=\sum_{i=1}^{n} \text { analyte-specific DHS score } i
\end{aligned}
$$

2.5. Sensory Evaluations. Sensory evaluations of samples were carried out by a trained sensory panel (Fraunhofer IVV) exhibiting no signs of any known illness at the time of examination. Training of panel members was accomplished by means of weekly training sessions with selected in-house developed odorant pens containing reference compounds and with a required minimum mean correctness threshold in odor identifications in ensuing tests. Sample pieces of approximately $5 \mathrm{~cm}$ diameter were cut from each mask, placed in covered glass jars with the inner face of the mask pointing upward, and presented to the panel. Quantitative descriptive analyses (QDAs), as well as overall odor intensity and hedonic ratings, were performed on each of the 12 masks. Panelists were required to open the lid and then immediately smell the samples and record their odor impressions. In an initial session, six assessors named the odor attributes of each sample, which were subsequently compiled for the most frequent attributes and panel consensus. In a second session, the six trained panelists rated the overall intensity of each attribute for each sample on a scale from 0 (no perception) to 10 (strong perception). A larger panel comprising 13 panelists (six trained and seven untrained) also completed hedonic ratings on a scale from 0 (strong disliking) to 5 (neutral) to 10 (strong liking) as well as ratings of the overall odor intensity on a scale from 0 (no perception) to 10 (strong perception). The mean values of all ratings are reported.

2.6. Exposure Assessment through Simulated Use of Masks. We developed an innovative setup based on a doll's head to simulate and assess realistic exposure while wearing a costume mask. A doll's head intended for cosmetic training (purchased online from Amazon, Luxembourg, Luxembourg) was used for simulated exposure assessments. The dimensions of the head were $21 \mathrm{~cm}$ from chin to crown, $20 \mathrm{~cm}$ from the tip of the nose to back of the head, and $16 \mathrm{~cm}$ between the two ears, resembling a small adult human head. The foam inside the doll's head was removed until the nose was freely accessible from the inside, and it was left to ventilate for 2 months under a laboratory fume hood prior to use. Two holes (approximately $1 \mathrm{~cm}$ diameter) were cut into the nose to mimic nostrils, and two PTFE tubes were connected to the nostrils through the inside of the doll's head to simulate exhalation and inhalation. The head was mounted on a stable cardboard base and affixed with low-emission aluminumcoated tape. A picture of the system is presented in Figure 1.

Average at-rest inhalation and exhalation flows for adults are around $6 \mathrm{~L} \cdot \mathrm{min}^{-1}{ }^{22}$ Pure $\mathrm{N}_{2}$ was flushed through the exhalation tube at a rate of $6.00 \pm 0.20$ or $13.00 \pm 0.25 \mathrm{~L} \cdot \mathrm{min}^{-1}$, with the latter simulating breathing during moderate activity and resembling the maximum flow rate of the pump used to simulate inhalation. The inhalation tube was connected to two pumps via a T-piece. One of the pumps (a gas sampler GS 212, Type 170110, DESAGA GmbH, Heidelberg, Germany) ran continuously at a sampling flow of either $5.90 \pm 0.20$ or $12.90 \pm 0.20 \mathrm{~L} \cdot \mathrm{min}^{-1}$ to simulate inhalation. The second pump (SG350ex, GSA Messgerätebau GmbH, Ratingen, Germany) ran continuously with a flow rate of $100 \mathrm{~mL} \cdot \mathrm{min}^{-1}$ and was regularly used for active gas sampling $(200 \mathrm{~mL}, 2 \mathrm{~min})$ to capture any released volatiles on conditioned Tenax TA TD tubes spiked with internal standard (described in section 2.3) according to ISO 16000$6 .^{23}$ Blanks were sampled before the masks were placed on the doll's head to ensure low background VOC levels of the system (inhaled concentration of cyclohexanone was below $2.0 \mathrm{mg} \cdot \mathrm{m}^{-3}$ for blank samples; blank values were subtracted to obtain background-corrected values).

Ambient temperature $T$ (varying from 20.9 to $25.4{ }^{\circ} \mathrm{C}$ ) and relative humidity $H$ (varying from 39.5 to $64.8 \%$ ) were measured directly beside the doll's head immediately before and after each experiment. Exhalation and inhalation flow rates were checked with a gas counter (G 1.6 RF 1, Schlumberger, Amsterdam, The Netherlands) before each experiment.

VOC exposure assessments on the doll's head system were performed on two types of masks, selected on the basis of them exhibiting the highest overall VOC emissions, as determined via DHS analyses (described in section 2.4; results presented in section 3.2). Specifically, samples 9 and 10 were used in these experiments, whereby new batches of the same mask types (9B, 9C, and 10B) were used.

2.7. Qualitative and Quantitative Gas Chromatography/ Mass Spectrometry Analysis of Gas Samples and Risk 
Assessment. The Tenax TA TD tubes containing the adsorbed VOCs (either from DHS sampling of mask emissions or from gas sampling from the inhalation tube in the exposure simulation experiments) were analyzed using GC/MS according to ISO 160006. ${ }^{23}$ Thermal desorption was performed with a thermal desorption unit (TDU; Gerstel) connected to a gas chromatograph 6890 that was coupled to a mass selective detector 5975 (both Agilent, Waldbronn, Germany). The TDU was operated with a helium gas flow of 51.5 $\mathrm{mL} \cdot \mathrm{min}^{-1}$ and the following temperature program: $25^{\circ} \mathrm{C}$ for $0.2 \mathrm{~min}$; heating to $280{ }^{\circ} \mathrm{C}$ at $700{ }^{\circ} \mathrm{C} \cdot \mathrm{min}^{-1} ; 280^{\circ} \mathrm{C}$ held for $2 \mathrm{~min}$. During thermal desorption, analytes were cryotrapped at $-150{ }^{\circ} \mathrm{C}$ with liquid $\mathrm{N}_{2}$ (Linde) in the cold injection system (CIS; Gerstel) equipped with a liner filled with deactivated glass wool (Gerstel). After desorption, the CIS was heated to $285{ }^{\circ} \mathrm{C}$ at $12{ }^{\circ} \mathrm{C} \cdot \mathrm{s}^{-1}$ and then held at $285^{\circ} \mathrm{C}$ for $15 \mathrm{~min}$. Injections were carried out either splitless (following DHS sampling) or with a split of 1:400 (1:20 at the CIS and 1:20 at the TDU in exposure simulation and microchamber experiments).

The GC system was equipped with a DB-5MS column $(60 \mathrm{~m} \times$ $0.32 \mathrm{~mm}$ i.d., $1.00 \mu \mathrm{m}$ df, J \& W Scientific, Folsom, CA, USA). Helium gas was used as a carrier gas at a constant flow rate of $1.4 \mathrm{~mL}$. $\min ^{-1}$. The GC oven temperature program commenced with $45{ }^{\circ} \mathrm{C}$ for $0.5 \mathrm{~min}$, before being heated to $200{ }^{\circ} \mathrm{C}$ at $12{ }^{\circ} \mathrm{C} \cdot \mathrm{min}^{-1}$, held for 5 min at $200{ }^{\circ} \mathrm{C}$, then heated to $280^{\circ} \mathrm{C}$ at $20^{\circ} \mathrm{C} \cdot \mathrm{min}^{-1}$, and held at 280 ${ }^{\circ} \mathrm{C}$ for $10 \mathrm{~min}$.

The temperatures of the transfer line, quadrupole, and ion source were 295,150 , and $230{ }^{\circ} \mathrm{C}$, respectively. The MS was operated in combined SIM/full-scan mode. The mass range for acquiring full-scan MS data was set to $m / z 40-450$ and measured at a rate of 3.5 scans. $\mathrm{s}^{-1}$ in unit resolution. The target compounds were identified by comparing their retention times and full-scan mass spectra with those of authentic standards. SIM data were acquired with a dwell time of $10 \mathrm{~ms}$ per ion and used to quantify target compounds in relation to the internal standard cyclodecane of known concentration. The resolution of the MS was set to low. One quantifier and one or two qualifier ions were assigned to each analyte. SIM parameters are reported in the Table S2.

Analytes were quantified by calibration with authentic standards, applying conditioned and internal standard spiked TD tubes (section 2.3). A volume of $1 \mu \mathrm{L}$ of the prepared calibration solution in ethyl acetate (stored in a freezer at $-18{ }^{\circ} \mathrm{C}$ ) was added using a tube spiking system (Gerstel) with a rinsed $10 \mu \mathrm{L}$ microvolume syringe. The tubes were then dried with $500 \mathrm{~mL}$ of $\mathrm{N}_{2}$ at a flow rate of $100 \mathrm{~mL} \cdot \mathrm{min}^{-1}$ and analyzed as described above. A representative calibration curve is presented in Figure S2.

Data were processed by using the MassHunter Quant Software (version B.06.00, Agilent). The results were converted to concentrations in air by dividing the measured amount of analyte by the volume of air that was sampled and compared to the DNEL values published on the European Chemicals Agency (ECHA) website. ${ }^{24}$ Inhalation DNELs for the general population are well-suited for a risk assessment based interpretation of the emissions measurement data in an exposure scenario that involves the wearing of costume masks over a few hours. Contrarily, the European lowest concentration of interest (EU-LCI) values, which are commonly used to assess the safety of construction products, refer to emission test chamber measurements with air sampling performed 28 days after chamber loading. ${ }^{25,26}$ Similar to DNELs, EU-LCI values are derived toxicologically according to the ECHA guidance Chapter R. $8,{ }^{27}$ but the applied assessment factors are specifically adapted to prolonged exposure. Older EU-LCI values were derived from occupational exposure limits (OELs) with conservative considerations for vulnerable populations such as children. ${ }^{28}$ Conservative assessment factors make the DNEL also applicable to the general population. ${ }^{27}$ Moreover, the ECHA guidance $^{27}$ states that, for inhalation exposure periods exceeding 15 min, the long-term (chronic) DNEL should usually be applied. However, an acute/short-term DNEL should be set for acutely toxic substances if peak exposure levels significantly exceed the long-term DNEL. Thus, both acute/short-term and long-term DNELs were considered in this study.
2.8. Analysis of Gas Samples by Gas Chromatography/ Olfactometry. GC/O in combination with DHS sampling was used to identify odorous substances. DHS-GC/O avoids the rather laborious SAFE extraction step and allows the sample to be studied online at ambient temperature. ${ }^{29}$ DHS sampling prior to $\mathrm{GC} / \mathrm{O}$ analysis was carried out in a manner similar to the method described in section 2.4, with the following exceptions: the extraction step was carried out at $28^{\circ} \mathrm{C}$ because the proximity of the DHS station and the heated olfactometry detector line $\left(250{ }^{\circ} \mathrm{C}\right)$ prevented a lower stable temperature during sampling; furthermore, no internal standard was used because of the qualitative nature of the analyses. Experiments were conducted with samples $9 \mathrm{~A}$ and $10 \mathrm{~A}$ in triplicate. Odors were considered when they were detected by the operator in at least two independent DHS-GC/O experiments.

The TD-GC methods resembled those described in section 2.7, albeit using a HP-5MS column $(30 \mathrm{~m} \times 0.25 \mathrm{~mm}$ i.d., $0.25 \mu \mathrm{m}$ df, J \& W Scientific). The flow rates and capillary length were calculated with the ODP column calculator software (Gerstel). The effluent at the end of the GC column, at a flow rate of $1.47 \mathrm{~mL} \cdot \mathrm{min}^{-1}$, was split into two equal flows of $0.73 \mathrm{~mL} \cdot \mathrm{min}^{-1}$ each. A first capillary, with a length of $79 \mathrm{~cm}$ heated to $250{ }^{\circ} \mathrm{C}$, led to an olfactory detection port (ODP3, Gerstel) that was held at $250{ }^{\circ} \mathrm{C}$. The same operator smelled all samples from retention times 3.6 to $8.0 \mathrm{~min}$ (in a preliminary experiment, no odors were detected beyond these retention times). A second capillary of $51 \mathrm{~cm}$ length led through the GC oven to the MS. The MS method is described in section 2.7.

To identify analytes associated with the detected odors, $1 \mu \mathrm{L}$ of a mixture of authentic reference compounds in dichloromethane $(\sim 25$ $\mathrm{ng} \cdot \mu \mathrm{L}^{-1}$ ) was transferred into microvials (Gerstel), placed inside an empty TD tube (Gerstel), and measured as described for Tenax TAloaded tubes (section 2.7). The analytes were identified by comparing their retention indices ${ }^{30}$ and mass spectra with those of the reference compounds. According to the ODP column calculator software, a delay of $0.8 \mathrm{~s}$ should be applied between MS and olfactometric detection. This delay was verified experimentally with an odorous model compound ( $p$-cresol, $0.7 \mathrm{~s}$ ).

2.9. Surface Emissions Measurements with a Microchamber. Surface emissions measurements on the costume mask samples were carried out with a miniaturized emission chamber to investigate the potential of such a device for the routine assessment of VOC emissions in complex exposure scenarios. A microchamber/thermal extractor device ( $\mu$-CTE250, Markes International, Llantrisant, U.K.) with four chambers, each with a volume of $114 \mathrm{~mL}$, was utilized for these measurements. The microchamber parameters were adapted to approach the area-specific flow rate of the doll's head setup $(2.80 \mathrm{~mL}$. $\left.\mathrm{cm}^{-2} \cdot \mathrm{min}^{-1}\right)$ : The total area of the inner surface of a mask was estimated by cutting a mask of type 9 (horse) into small geometrical pieces and summing up their individual areas $\left(2141 \mathrm{~cm}^{2}\right)$. The same surface area was assumed for mask 10 . The internal volume of the mask $(6.0 \mathrm{~L})$ was obtained by measuring the volume of water needed to completely fill the mask after sealing all holes with tape. By subtracting the mean volume of a human head $\left(3.2 \mathrm{~L}^{31}\right)$, the gas volume between the head and the mask was calculated to be approximately $2.8 \mathrm{~L}$. As the microchamber has a diameter of $6.4 \mathrm{~cm}$, mask pieces of ca. $32 \mathrm{~cm}^{2}$ were placed inside the chamber (inner side facing upward) for surface emissions measurements (schematic description in Figure S3). The chamber volume was decreased to $42 \mathrm{~mL}$ with metal spacers (Markes; height, $1.3 \mathrm{~cm}$ ) and the $\mathrm{N}_{2}$ flow was set to $88 \pm 6 \mathrm{~mL} \cdot \mathrm{min}^{-1}$, resulting in an area-specific flow rate of $2.74 \mathrm{~mL} \cdot \mathrm{cm}^{-2} \cdot \mathrm{min}^{-1}$. The temperature of the chamber (measured with the integrated sensor) was $23 \pm 1{ }^{\circ} \mathrm{C}$. The relative humidity, $H$ (measured in one chamber with a HI 9565 sensor from Hanna, Vöhringen, Germany), was $45.4 \pm 1.8 \%$.

For comparative measurements, one (sample 9C) or two pieces (sample 10B, in two separate chambers) of $6.4 \mathrm{~cm}$ diameter were cut from the neck of the masks with a precision knife (NT cutter, Osaka, Japan) and placed in the microchamber at the same time that the masks (minus the pieces cut from the neck region) were placed on the doll's head. Gas samples were collected at the outlet of the chamber onto conditioned Tenax TA TD tubes spiked with internal standard 

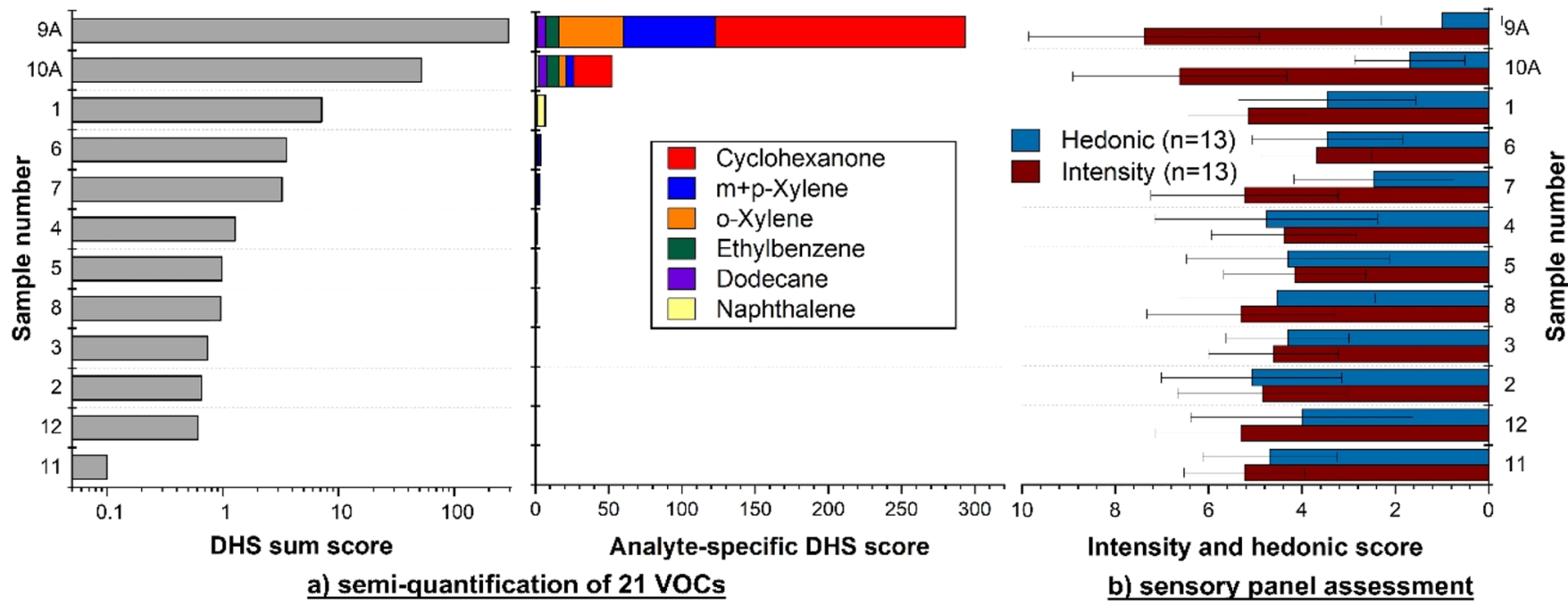

Figure 2. DHS sum scores (left, logarithmic $x$-axis scale) and analyte-specific DHS scores (middle, linear $x$-axis scale) of the emitting target analytes (a) and results of the sensory evaluation (right, mean values of hedonic ratings and overall odor intensities, $n=13$ panelists, error bars represent SDs) (b) of the 12 mask samples.

(sampling time, 2 min $15 \mathrm{~s}$ ) at the same time that they were collected from the doll's head and analyzed following the protocol described in section 2.7 .

To simulate worst-case, real-life conditions for the analyses, the temperature inside mask 11 was measured when it was worn in the sun on a hot summer's day (outside temperature, ca. $35^{\circ} \mathrm{C}$ ), yielding a temperature of ca. $40{ }^{\circ} \mathrm{C}$. To mimic these conditions, in one experiment the temperature inside the chamber was fixed to $40 \pm 1$ ${ }^{\circ} \mathrm{C}(H=44.1 \pm 0.3 \%)$. In a different run, the emissions were measured at $T=23 \pm 1{ }^{\circ} \mathrm{C}$ and $H=42.6 \pm 0.1 \%$ (sampling time, 1 $\min 45 \mathrm{~s}$ ) with a $40 \%$ increased area-specific flow rate of $3.85 \mathrm{~mL}$. $\mathrm{cm}^{-2} \cdot \mathrm{min}^{-1}$ (resulting from the system's maximum possible flow rate of $124 \pm 2 \mathrm{~mL} \cdot \mathrm{min}^{-1}$ when the humidifier was used).

\section{RESULTS AND DISCUSSION}

3.1. Polymer Characterization. Pyrolysis-GC/MS analysis of the masks indicated that each mask was at least in part composed of polyvinyl chloride (PVC), as identified through the presence of typical PVC degradation products ${ }^{32}$ in each individual sample (two representative pyrograms are presented in Figure S4). In addition, Beilstein tests on samples 9A and $10 \mathrm{~A}$ yielded the expected green flame that is characteristic of halide-containing polymers, such as PVC. In contrast, all other samples melted without burning (see Figure S5), which can be attributed to the presence of halogen-free flame retardants in their polymeric matrixes.

3.2. Volatile Profiles and Odor Perception. The VOC emissions profiles from the mask samples, as determined semiquantitatively via DHS-GC/MS, were compared with the odor profiles evaluated by the sensory panel. A plot of the DHS sum scores for each sample, whereby the scores represent the sum of signal intensities of 21 individual analytes (comprising the compounds with the highest signal intensities), shows that two masks (samples 9A and 10A) exhibited particularly high VOC emissions (Figure 2a, left). Cyclohexanone, xylenes, and ethylbenzene were detected as the most abundant signals in the chromatograms of these two samples (Figure 2a, right; also compare Figure S6). Xylenes are known to be neurotoxic. ${ }^{33}$ Furthermore, $o$-xylene and naphthalene, which is classified as possibly carcinogenic to humans ${ }^{34}$ and was detected in sample 1 , are precursors in the synthesis of phthalic anhydride, ${ }^{35}$ a reactant for the production of phthalate-based plasticizers.
Their presence as impurities in soft plastics, such as PVC, which frequently contain this class of additives, is therefore explicable. Indeed, bis(2-ethylhexyl) phthalate (DEHP), a regulated phthalate with suspected endocrine disrupting properties, was detected in sample 9A via pyrolysis-GC/MS (see Figure S4). Cyclohexanone, on the other hand, is used as a PVC adhesive and can potentially induce contact dermatitis. ${ }^{36}$ Cyclohexanone inhalation also induced hepatotoxicity and nephrotoxicity in rats. ${ }^{37}$ This compound was detected in several other studies that investigated emissions and odors from polymer-based products. ${ }^{7,15,38}$

Notably, the sensory panel rated the same two samples featuring the highest DHS sum scores (9A and 10A) as having the highest odor intensities and lowest hedonic ratings (Figure 2b), while samples with lower emissions (low DHS sum scores) were rated with less intense odors and higher hedonic ratings. Although the limited sample size makes it difficult to draw general conclusions, it seems likely that products rated as having a bad smell are of low overall quality, which is reflected in elevated VOC emissions.

3.3. Odor Profiles. The sensory profiles from the QDA of the 12 mask samples are depicted in Figure 3. The two masks that exhibited the highest overall odor intensities and emissions (i.e., samples 9A and 10A) feature rather unique profiles: both were characterized as rubber-like (reference compound in the odorant pen representing this attribute,

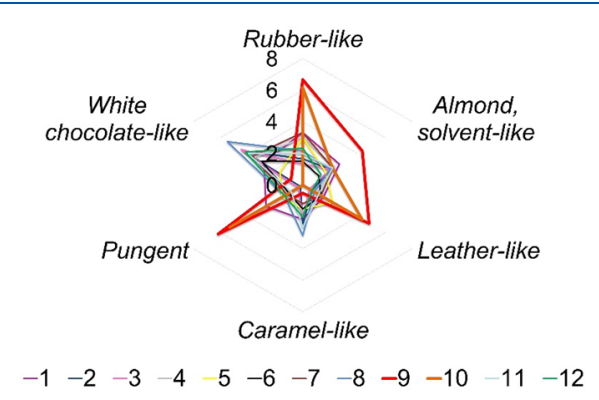

Figure 3. Odor profiles of the predominant six attributes of the 12 mask samples that were assigned the highest scores (mean scores of six trained panelists). 


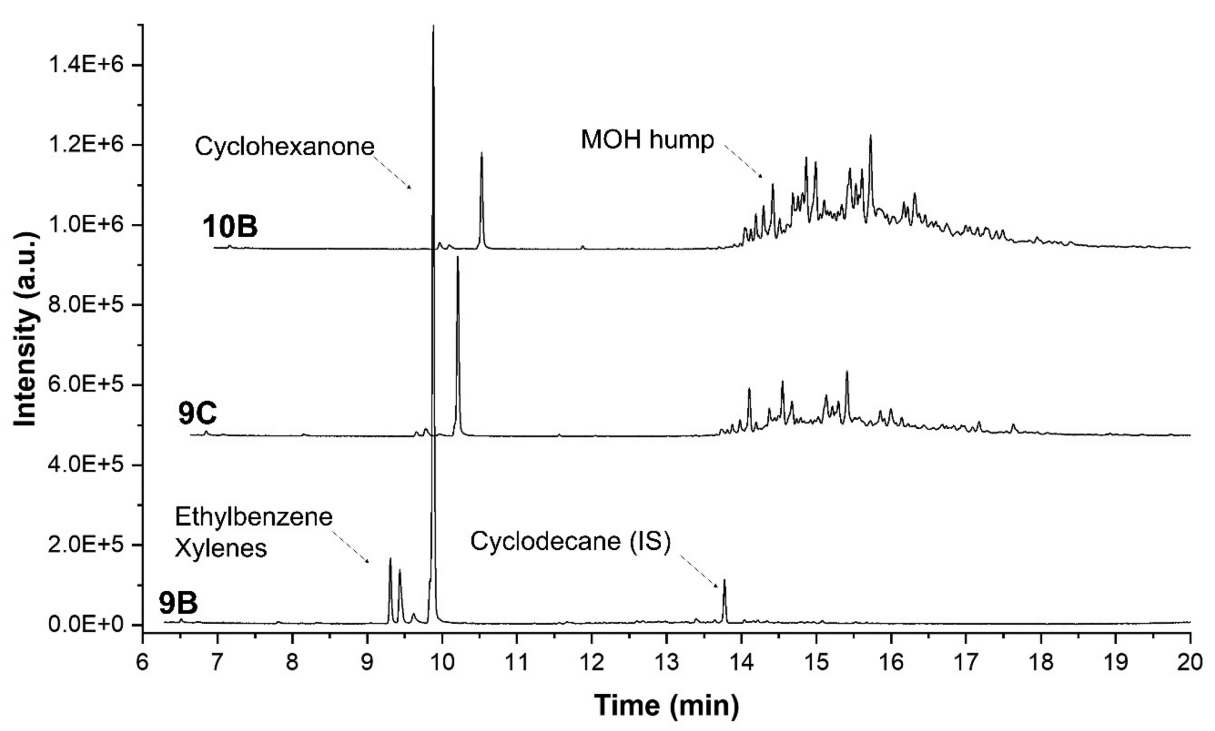

Figure 4. GC/MS traces (scan mode) of gas samples taken from the inhalation tube during the first 2 min after placement of the mask on the doll's head during simulated exposure assessments.
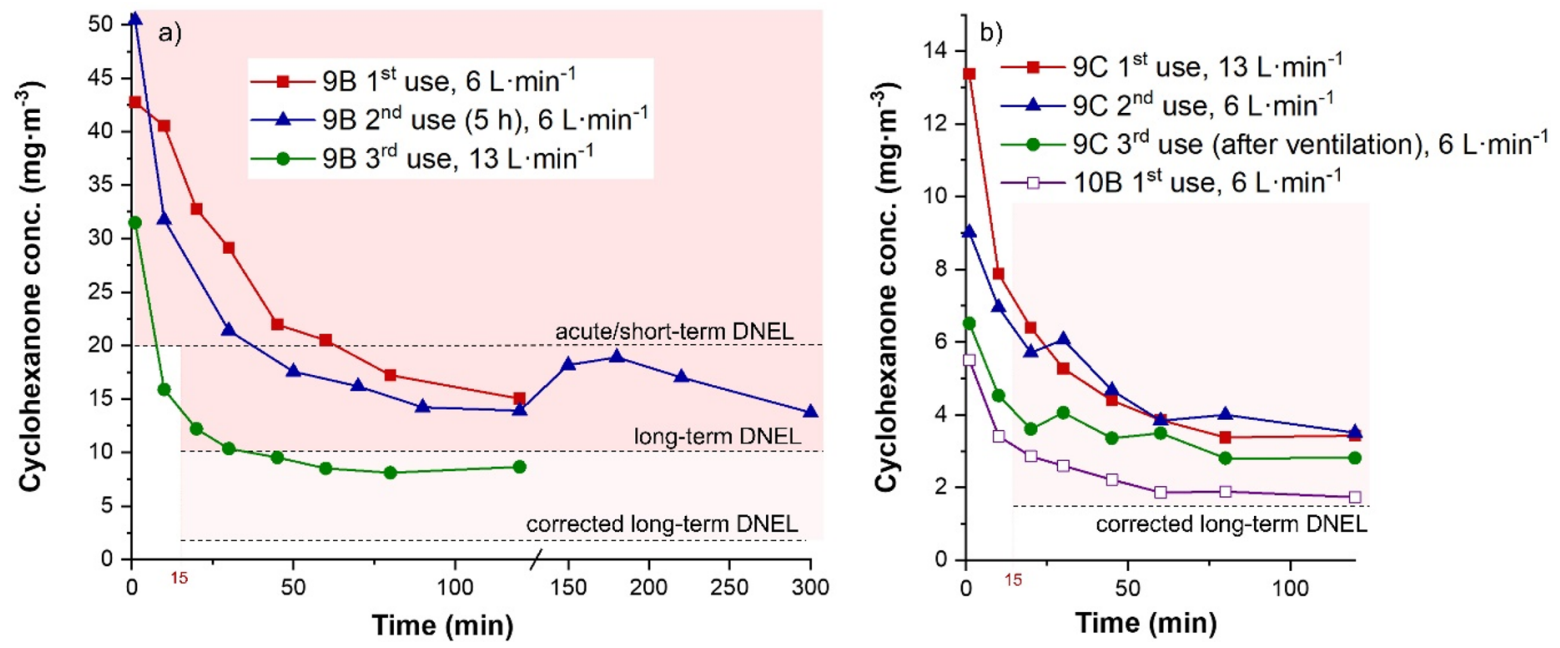

Figure 5. Kinetic profiles depicting inhalable concentrations of cyclohexanone while wearing three different costume masks, 9B (a) and 9C and 10B (b), as determined with the doll's head exposure simulation setup. DNEL threshold values, as derived by the industry registrants (acute/short-term, long-term after $15 \mathrm{~min}$ ) or in this work (corrected long-term), are shown as reference. Long-term DNELs are usually applied for exposures exceeding 15 min. ${ }^{27}$ Colored regions indicate regimes where cyclohexanone DNELs were exceeded.

benzothiazole), pungent (1-penten-3-one), and leather-like (3methylphenol), which are attributes that are usually perceived as unpleasant. These attributes might therefore explain the very low hedonic scores of these two samples (see Figure 2b). By comparison, the other 10 masks were characterized as exhibiting white-chocolate-like (cocoa butter), caramel-like (ethyl maltol), or almond, solvent-like (acetophenone) odors, which are typically perceived as more pleasant odors and thus explain their higher hedonic ratings. This could imply that those 10 samples were fragranced, although related compounds were not among the highest peaks detected during DHS-GC/MS experiments.

DHS-GC/O-MS analysis of samples $9 \mathrm{~A}$ and $10 \mathrm{~A}$ yielded different attributes of the odor-active compounds present in the two samples, as is evident from the list in Table S3, despite their similar descriptive sensory profiles. The substances with the highest emissions in the DHS-GC/MS analyses (see Figure 2a) were largely also identified in the DHS-GC/O-
MS analyses, as determined via their chromatographic retention indices (measured with reference compounds) and mass spectra. Interestingly, no odor was perceived for ethylbenzene and the xylenes in DHS-GC/O-MS, despite these compounds exhibiting high DHS scores of up to 9 and 63, respectively, in the DHS-GC/MS analyses. Only cyclohexanone, which had the highest assigned DHS score of 170, was perceived (flowery, grassy, solvent-like; RI $=913$, see Table S3). Wiedmer and Buettner characterized the odor as almondlike, inflatable-swimming-aid-like, ${ }^{16}$ but the subjective perception can be different among individual assessors. Overall, the comparison of DHS-GC/MS and DHS-GC/O-MS data sets for the two selected masks revealed that the substances with the highest measured emissions were not necessarily those causing the perceived odors. Notably, the intense odors could also arise from very volatile organic compounds (VVOCs) including solvents, which cannot be measured with the ISO 16000-6 approach. ${ }^{23}$ 
3.4. Emissions Assessments of Masks under Simulated Exposure Conditions. Figure 4 displays the GC/MS traces depicting the VOCs present in $200 \mathrm{~mL}$ of air sampled from the inhalation tube during the first 2 min after the mask was placed on the doll's head. Notably, masks 9 (horse) and 10 (unicorn) revealed very similar chromatograms: those two masks had the same town of origin and were similarly packaged and labeled, indicating a common source. The most abundant peaks corresponded to the same compounds detected in the DHS-GC/MS experiments (see Figure 2a and Figure S6), as expected. However, the chromatograms of samples $9 \mathrm{C}$ and $10 \mathrm{~B}$ featured a hump at later retention times that is characteristic for the volatile fraction of mineral oil hydrocarbons (MOHs). MOHs are sometimes used to soften PVC products. ${ }^{39}$ However, they might also have been transferred from printed cardboard packaging during storage. The bioaccumulative and carcinogenic potential of $\mathrm{MOHs}$ is under discussion. ${ }^{40}$

Samples 9B and 9C, which were masks of the same type but from different batches, exhibited significant differences in their emitted quantities of specific compounds. The amount of cyclohexanone emitted from mask $9 \mathrm{~B}$ was approximately 3 times higher than that from sample 9C. Similarly, mask 9C emitted approximately 12 times more MOHs than sample 9B, as quantified by comparison of the integrated peak areas. This indicates a need to characterize many different samples from the same article type to achieve a representative market control.

3.5. Exposure Assessments under Simulated Mask Use. Inhalation exposure estimates require that the inhaled concentrations of specific VOCs emitted from the masks are known as a function of exposure time. The exposure simulation experiments using the doll's head setup revealed kinetic profiles with a slightly faster decrease for compounds with lower boiling points (see Figure S7). The inhalation profiles of cyclohexanone, which was the most abundant compound in both the headspace and doll's head based analyses (see sections 3.2 and 3.5), are depicted in Figure 5.

Different aspects were addressed in these exposure simulation assessments. First, one mask model (sample 9B, horse mask) was studied in three consecutive experiments to investigate the repeated use of a single mask. The inhaled cyclohexanone concentrations during first use of this particular mask exceeded the DNEL for short-term systemic effects on the general population published on the ECHA website ${ }^{24}(20$ $\mathrm{mg} \cdot \mathrm{m}^{-3}$ ) by up to 2 times within the first $15 \mathrm{~min}$ of simulated wearing. The DNEL for long-term exposure $\left(10 \mathrm{mg} \cdot \mathrm{m}^{-3}\right)$ was exceeded over the entire $2 \mathrm{~h}$ measurement period (Figure 5a). Concentrations of xylenes and ethylbenzene were below the respective DNEL values; thus related data are not reported here. It is important to note that the DNELs for cyclohexanone were derived by the industry registrants in order to comply with the European REACH Regulation. It was not possible to reproduce how the registrants derived the cyclohexanone DNELs from the reported data on the ECHA website. ${ }^{24}$ Considering a recent study on cyclohexanone toxicity upon inhalation in rodents, ${ }^{37}$ which was not considered by the registrants, we derived long-term DNELs for workers and the general population of 8.1 and $1.4 \mathrm{mg} \cdot \mathrm{m}^{-3}$, respectively (see Table S4 and accompanying text; the latter DNEL is also indicated in Figure 5). The corrected DNEL of $1.4 \mathrm{mg} \cdot \mathrm{m}^{-3}$ was exceeded by up to 31 -fold during the first few minutes of wearing, and still by more than 10 times after $2 \mathrm{~h}$. As costume masks may be worn repeatedly for several hours, the corrected long-term DNEL is considered more appropriate than the acute DNEL that reflects a single use exposure. Acute DNELs are generally much higher than long-term DNELs as their derivation is based on lethality observed in animal studies. However, for potential hazardous properties of the masks, lethality is not an appropriate end point for consideration. When adjusting the measured cyclohexanone concentrations for shorter daily exposure, as suggested by the ECHA, ${ }^{41}$ the long-term DNEL is still significantly exceeded (see the Supporting Information for details). Of note, the EU-LCI threshold value for this substance $\left(410 \mu \mathrm{g} \cdot \mathrm{m}^{-3}\right)^{25}$ would have been exceeded by up to 128 -fold. However, EU-LCI values are intended to cover long-term exposures for substances emitting from building products, for which an initial off-gassing period without direct inhalation exposure is assumed (see section 2.7).

After this first exposure assessment, the mask was repacked in a gastight bag, stored at room temperature for 2 days, and then reassessed for inhalation exposure during second use. The inhaled cyclohexanone concentration reached a maximum of ca. $50 \mathrm{mg} \cdot \mathrm{m}^{-3}$ within the first $2 \mathrm{~min}$, which is similar to the first assessment. Two mechanisms contribute to the kinetics of the emissions processes: diffusion of the VOCs within the material along a concentration gradient and partitioning between the material surface and the surrounding air. During the first-use exposure assessment, emissions decreased over time because diffusion was rate-limiting, leading to a steady decrease in the surface concentration of cyclohexanone. While the mask was being stored in the airtight bag, diffusion from the material core resupplied the surface with cyclohexanone that had previously been depleted during the emissions analysis. When the mask was unpackaged and the second measurement started, cyclohexanone was emitted at similar concentrations. Small differences probably result from slight deviations during gas sampling or a slightly different position of the mask on the doll's head. Importantly, cyclohexanone concentrations were also observed to exceed both long-term exposure DNELs for at least $5 \mathrm{~h}$ in the second-use exposure assessment. The inhaled amounts of cyclohexanone vapors when wearing this mask are therefore concerning, not only during the first few minutes, but also during repeated or longterm use.

Breathing patterns that are characterized by higher inhalation/exhalation frequencies are typically observed during physical activity or when experiencing strong emotions. As such, the influence of the breathing rate on the cyclohexanone exposure was explored by varying the flow rate from $6 \mathrm{~L} \cdot \mathrm{min}^{-1}$ (at-rest breathing ${ }^{22}$ ) in the first two emissions measurements to $13 \mathrm{~L} \cdot \mathrm{min}^{-1}$ in a third assessment carried out 8 days later. In this scenario, the cyclohexanone concentrations were approximately half of those during the previous measurements. The approximately doubled flow rate dilutes the gas phase concentration of cyclohexanone. Additionally, it is also possible that the surface concentration decreased during the previous two trials, with a lower total concentration of cyclohexanone remaining in the material. However, since the volume of inhaled air per unit of time increases accordingly, the total amount of inhaled VOC remains similar.

The emissions from another specimen of the same mask type (9C, horse mask) were measured to study possible inhomogeneity between similar samples (Figure 5b). In this case, exposure to cyclohexanone was much lower than for 
sample 9B. Possible reasons for these differences could be the varying amounts of chemicals used during production, as well as different ambient conditions (air change rate, temperature, humidity) that the masks had been exposed to since manufacturing. In these experiments, the first- and seconduse assessments were carried out within 2 days, applying flow rates of 13 and $6 \mathrm{~L} \cdot \mathrm{min}^{-1}$, respectively. The cyclohexanone concentrations were observed to be higher in the first few minutes of the first-use assessment at high flow rate compared to the second-use assessment at low flow rate. Presumably, the lower total amount of cyclohexanone in sample 9C compared to $9 \mathrm{~B}$ further depleted to a significant extent in the first measurement at high flow.

The third measurement was carried out after venting of the mask under controlled conditions in an emission chamber (203 L, air change rate $0.5 \mathrm{~h}^{-1}, T=23{ }^{\circ} \mathrm{C}, \mathrm{H}=50 \%$ ) for $14 \mathrm{~h}$ in order to examine any influence that ventilation might have on emission rates. Two main observations were made. First, ventilation seemingly acted to reduce high initial emissions, whereby the concentrations of cyclohexanone in the first few minutes of the inhalation exposure simulation were lower compared to at the beginning of the previous trial. This likely relates to the air exchange acting to deplete compounds from the material surface compared to packaged storage. On the other hand, the initial concentration is still higher than the concentration measured at the end of the preceding seconduse assessment. This highlights that, even under conditions facilitating ventilation, significant amounts of cyclohexanone may accumulate on the mask surface.

The cyclohexanone concentration was determined to be $18.65 \pm 0.08 \mathrm{mg} \cdot \mathrm{m}^{-3}(n=2)$ in the $203 \mathrm{~L}$ test chamber directly before removing the mask after ventilating it for $14 \mathrm{~h}$. This corresponds to $126 \mu \mathrm{g} \cdot \mathrm{m}^{-3}$ cyclohexanone in a $30 \mathrm{~m}^{3}$ room, which is 3 times lower than the EU-LCI ${ }^{25}$ and 11 times lower than the DNEL derived in Table S4. Items such as costume masks are emissions sources not only while being worn, but also when they are stored indoors. Scenarios with multiple masks-for instance in retail environments-might lead to higher concentrations that ultimately may exceed threshold values. The Scientific Committee on Health, Environmental and Emerging Risks (SCHEER) is currently working on an opinion on toxicological reference values for VOCs (including cyclohexanone) emitted from toys in such scenarios: ${ }^{42}$ this was requested after high VOC concentrations were detected in emission chamber testing of squishy toys. ${ }^{9}$

Finally, a comparative analysis with mask 10B (unicorn) revealed that the cyclohexanone inhalation exposure was lowest for this mask yet exhibited kinetic profiles similar to those in masks 9B and 9C (Figure 5b). The PVC-based matrixes of both masks probably govern the release kinetics of cyclohexanone. Of note, the long-term DNEL of $1.4 \mathrm{mg} \cdot \mathrm{m}^{-3}$ (derived in Table S4) would be exceeded for all three masks studied (see Figure 5).

It is noteworthy that a combined exposure assessment of all VOCs found in this study may be useful to provide a more comprehensive risk assessment that takes into account possible additive effects. This might add to the concern of VOCs released from costume masks. A thorough mixture assessment would require comparable effect data for all these VOCs in order to determine their individual relative effect potencies. Additionally, a prerequisite for combined additive mixture effects is the same, or a similar, mode of action or at least the same type of effect. Considering the complexity of such an assessment, this was not pursued in the present study. Furthermore, it is emphasized that cyclohexanone was the predominant VOC in this study (see Figure S7) and that it exceeded guideline threshold values even as a single component.

3.6. Surface Emissions Measurements with a Microchamber: Toward Facilitating Market Control. Using a microchamber to investigate surface emissions may be advantageous for control authorities of consumer products, which rely on standardized and cost-effective experimental configurations for a harmonized market control.

Figure 6 displays data from the comparative measurements of cyclohexanone emissions as a function of time for samples

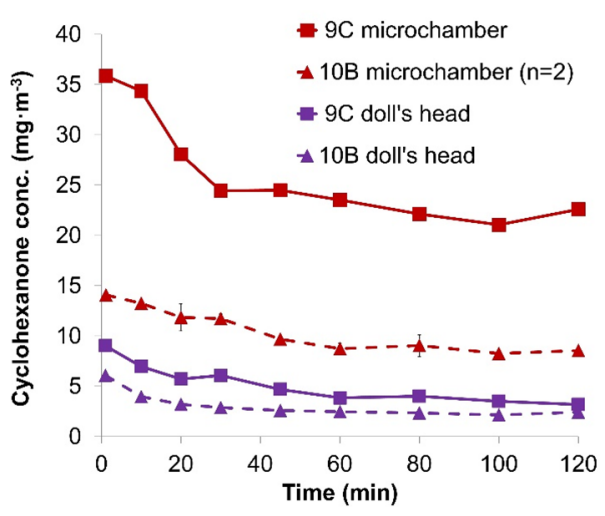

Figure 6. Comparison of cyclohexanone concentrations emitted from samples 9C and 10B, as measured simultaneously with the microchamber (representative sample piece) and doll's head exposure simulation setup (rest of the whole mask).

9C and 10B from both the microchamber and exposure simulation configurations. The kinetic profiles obtained from the two analytical experiments were similar. However, although the gas phase concentrations measured in the microchamber are of the same order of magnitude as the inhalable concentrations determined in the exposure simulation measurements, they are significantly higher by a factor of 2.3-7.1 for both masks. When adjusting the area-specific flow rate in the microchamber to reflect the conditions of the doll's head setup (see section 2.9), the inhalation/exhalation flows were considered as being equally distributed in the space between the mask and the doll's head. In reality, however, the area-specific air flow is presumably much higher near the site where the air exits and enters the tubes (i.e., the nostrils) than elsewhere. As such, a smaller surface contributes to the emissions in the more realistic doll's head setup and fewer molecules are emitted per unit surface area. Hence, a sampling time dependent correction factor is needed, which was found to be also analyte- and sample-specific (Figure 7).

In a final experiment, the emitted cyclohexanone concentrations from different pieces of the same mask were investigated, as were the effects of increased temperature and flow rate (Figure 8).

Comparative, simultaneous emissions measurements of three different pieces of mask $9 \mathrm{~A}$ in three compartments of the microchamber at $23{ }^{\circ} \mathrm{C}$ and a flow rate of $90 \mathrm{~mL} \cdot \mathrm{min}^{-1}$ indicated a low relative standard deviation (SD), which varied from 3.7 to $12.0 \%$ between different sampling time points. The variation was much lower than between different masks of the same type that were measured on the doll's head (see 9B and 

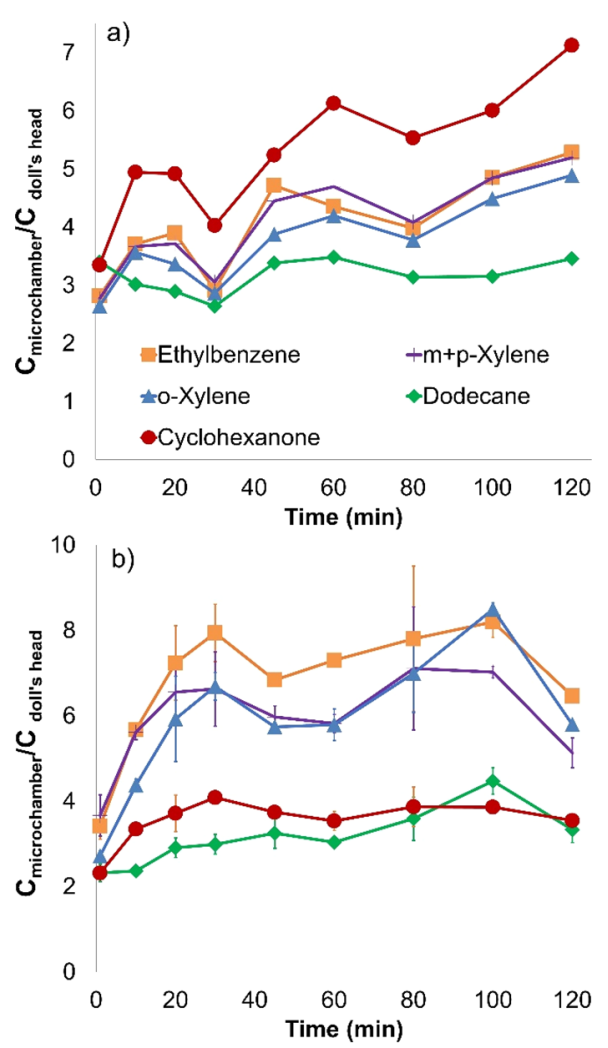

Figure 7. Ratio of gas phase concentrations of six analytes measured in the microchamber and with the doll's head exposure simulation setup from sample 9C (a, $n=1)$ and sample 10B (b, $n=2)$. Error bars represent $\mathrm{SDs}$ for repeated analyses.

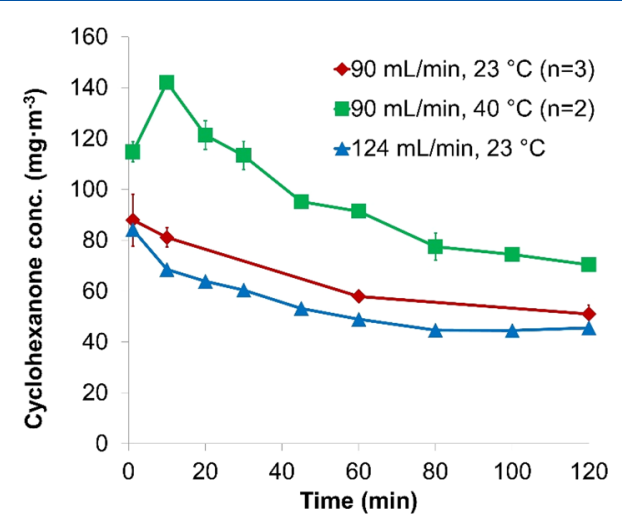

Figure 8. Influence of mask homogeneity and increased temperature and flow rate on the cyclohexanone concentrations emitted from sample 9A as measured in the microchamber. Error bars represent SDs for repeated analyses (see figure legend).

9C in Figure 5). This suggests that for a preliminary assessment it would be sufficient to analyze a single piece per mask in the microchamber, facilitating multiplexing.

An increase in temperature inside the chamber from 23 to $40{ }^{\circ} \mathrm{C}$ to simulate the temperature beneath the mask on a warm summer's day led to up to a 1.8 -fold increase in emissions. This highlights the fact that temperature is an important parameter that must be taken into account in exposure assessments. Of note, the influence of temperature could not be studied conveniently with the doll's head setup because measurements were carried out in a laboratory at room temperature.
Finally, the influence of the air change rates on the emissions profile to simulate higher inhalation/exhalation flows indicated that cyclohexanone emissions decrease with a higher air exchange, as similarly observed for sample 9B in the doll's head setup (see Figure 5a).

\section{SUMMARY AND OUTLOOK}

While standardized methods to assess human exposures of VOC emissions in indoor environments exist, ${ }^{26,43}$ knowledge about VOC exposure in more complex emissions scenarios is scarce. In this study, we investigated which gas phase concentrations of VOCs are relevant for a realistic exposure assessment when costume masks are worn. In the particular case of masks, inhalation takes place very close to the emissions source, which increases the probability that harmful substances are inhaled at elevated concentrations and for prolonged periods.

The odors of 12 different polymer-based costume masks were characterized by a sensory panel, which identified two masks as having particularly intense and unpleasant smells. DHS-GC/MS experiments revealed that the same two masks yielded the highest DHS sum scores, which we previously introduced as a measure for the total target VOC emissions. ${ }^{10}$ However, DHS-GC/O analysis indicated that the VOCs with the highest detected emissions (cyclohexanone, ethylbenzene, and xylenes) were not necessarily responsible for the unpleasant smell of the masks. Still, in the subset of samples studied, masks with a bad smell seem to be of low overall quality, as represented by their elevated VOC emissions.

Furthermore, we developed an experimental setup that simulates inhalation exposure based on the use of a doll's head. This novel setup enabled simulation of exhalation and inhalation at realistic flow rates and facilitated sampling of the inhaled air containing relevant VOCs that are emitted from worn masks. The data from one mask sample revealed that the inhaled concentration of cyclohexanone exceeded the industry registrants derived no-effect level (DNEL) threshold value for short-term use by a factor of up to 2.5. Although the emissions decreased over time, the DNEL for long-term use was exceeded continuously over $5 \mathrm{~h}$ of mask wearing. Based on a recent inhalation toxicity study, ${ }^{37}$ we derived a significantly lower DNEL, which was exceeded up to 36-fold. This highlights the relevance of our exposure assessment results. Although the limited sample size makes it difficult to draw general conclusions, it is concerning that cyclohexanone emissions from 2 out of 12 randomly purchased masks exceeded the DNEL. It is also noteworthy that the cyclohexanone exposure was still significant after several uses, even if the mask was left to ventilate overnight. Although it might therefore be advisable to unpack such items outdoors and keep them there for a few days to outgas before use, the implementation of this recommendation cannot be checked. Hence, ventilation before first use is not a sufficient measure to protect consumers. Costume masks-like all other consumer products placed on the market-must meet the legal requirement to not pose a risk to consumers' health. Compliance with this regulation is the responsibility of the manufacturers and importers. Quality control processes during the production steps should be implemented to minimize the contents and release of hazardous VOCs and unpleasant odors to a level as low as reasonably achievable. This is particularly important as such masks may also be used by children. 
Surface emissions assessments with a low-volume emission test chamber (microchamber) were investigated as a potential alternative to the doll's head setup. Microchambers are standardized instruments that are lower in cost than largevolume chambers and might provide options for the development of standardized analytical methods to assess VOC emissions from consumer products by official control authorities. For the masks investigated here, both systems yielded similar emissions profiles. However, the implementation of analyte- and sample-specific correlation factors in the range of 2-9 proved necessary to match the chamber-derived VOC concentrations with those from the more realistic doll's head setup. Still, the microchamber allows for a quick and reproducible assessment of VOC emissions and for studying the influence of parameters, such as temperature or exhalation and inhalation flow rates on emission rates.

This work demonstrates that polymer consumer products, such as costume masks, that come into close contact with the consumer can pose a threat to human health due to the release and continuous inhalation exposure of toxicologically relevant volatiles. It remains to be demonstrated whether this is also an issue for other products used in medical and more recently also in public environments (e.g., for surgical and FFP masks intended to prevent airborne infections and for respiratory devices) and during occupational activities (e.g., for personal protective equipment of firefighters ${ }^{44}$ ). Additionally, less volatile compounds, such as PAHs and certain plasticizers (naphthalene and DEHP were each detected in one mask, respectively), may also need to be considered for long-term exposures during storage, e.g., in retail environments. Tandem chromatography techniques may provide further options to investigate the composition of emitting mineral oil hydrocarbons. Finally, a comprehensive exposure analysis for mask wearers also needs to consider the dermal exposure toward migrating chemicals via skin contact.

The protection of consumers against possible health hazards caused by VOC emissions from products can only be guaranteed if manufacturers, importers, and official control laboratories are aware of this complex topic. It is therefore crucial to develop harmonized analytical methods as well as to correctly interpret the results from a toxicological perspective.

\section{ASSOCIATED CONTENT}

\section{SI Supporting Information}

The Supporting Information is available free of charge at https://pubs.acs.org/doi/10.1021/acs.chemrestox.0c00414.

Tables S1 and S2: Details about chemical properties, standards, and analytical parameters; Table S3: results from GC/O experiments; Table S4 and associated text: derivation of corrected DNEL values; Figures S1-S7: mask sample pictures, cyclohexanone calibration curve, schematic diagram of microchamber setup, pyrolysisGC/MS chromatograms of two samples, picture from sample pieces after Beilstein tests, chromatograms from DHS experiments, kinetic profiles of low-boiling substances in comparison to cyclohexanone (PDF)

\section{AUTHOR INFORMATION}

\section{Corresponding Authors}

Morgane Even - German Federal Institute for Risk Assessment (BfR), Department of Chemical and Product Safety, 10589 Berlin, Germany; Department of Biology,
Chemistry, Pharmacy, Institute of Pharmacy, Freie Universität Berlin, 14195 Berlin, Germany; 이이.org/ 0000-0002-0241-8860; Email: Morgane.Even@bam.de

Alexander Roloff - German Federal Institute for Risk Assessment (BfR), Department of Chemical and Product Safety, 10589 Berlin, Germany; Email: Alexander.Roloff@ bfr.bund.de

\section{Authors}

Nils Lüttgert - German Federal Institute for Risk Assessment (BfR), Department of Chemical and Product Safety, 10589 Berlin, Germany

Jonathan Beauchamp - Department of Sensory Analytics, Fraunhofer Institute for Process Engineering and Packaging IVV, 85354 Freising, Germany; 이이.org/0000-0003$1405-7625$

Daniel Stalter - German Federal Institute for Risk Assessment (BfR), Department of Chemical and Product Safety, 10589 Berlin, Germany

Agnes Schulte - German Federal Institute for Risk Assessment (BfR), Department of Chemical and Product Safety, 10589 Berlin, Germany

Christoph Hutzler - German Federal Institute for Risk Assessment (BfR), Department of Chemical and Product Safety, 10589 Berlin, Germany

Andreas Luch - German Federal Institute for Risk Assessment (BfR), Department of Chemical and Product Safety, 10589 Berlin, Germany; Department of Biology, Chemistry, Pharmacy, Institute of Pharmacy, Freie Universität Berlin, 14195 Berlin, Germany

Complete contact information is available at: https://pubs.acs.org/10.1021/acs.chemrestox.0c00414

\section{Author Contributions}

Each author has participated in the work intellectually or practically and takes responsibility for the content of this article. M.E. and N.L. carried out the experimental work and data analysis. D.S. and A.S. carried out the assessment and calculation of DNEL values for cyclohexanone. M.E., A.R., C.H., J.B., and A.L. designed the study, analyzed data, interpreted the results, and contributed to the manuscript. The final version was approved by all authors.

\section{Funding}

We acknowledge the BfR intramural financial support of our studies (Project Grants 1322-631 and 1329-577).

\section{Notes}

The authors declare no competing financial interest.

\section{ACKNOWLEDGMENTS}

We thank R. Albrecht, M. Altemeier, M. Meyer, L. Hetzel, and P. Reichardt for excellent assistance. We also acknowledge Division 4.2 of the Federal Institute for Materials Research and Testing (BAM) for providing the gas sampler and gas counter and the Chemical and Veterinary Laboratory Office Ostwestfalen Lippe for providing sample 1 .

\section{ABBREVIATIONS}

BVL, German Federal Office of Consumer Protection and Food Safety-Bundesamt für Verbraucherschutz and Lebensmittelsicherheit; CIS, cold injection system; df, film thickness; DEHP, bis(2-ethylhexyl) phthalate; DHS, dynamic headspace; DNEL, derived no-effect level; ECHA, European Chemicals 
Agency; EU-LCI, European lowest concentration of interest; FFP, filtering facepiece; GC, gas chromatography; GC/O, gas chromatography/olfactometry; i.d., internal diameter; IS, internal standard; MS, mass spectrometry; $\mathrm{MOHs,} \mathrm{mineral}$ oil hydrocarbons; $\mathrm{N}_{2}$, nitrogen; ODP, olfactory detection port; o.d., outer diameter; $\mathrm{PAH}$, polycyclic aromatic hydrocarbon; PTFE, polytetrafluoroethylene; PVC, polyvinyl chloride; QDA, quantitative descriptive analysis; $\mathrm{REACH}$, registration, evaluation, authorization, and restriction of chemicals; RI, retention index; SAFE, solvent-assisted flavor evaporation; SCHEER, Scientific Committee on Health, Environmental and Emerging Risks; SD, standard deviation; SIM, selected ion monitoring; $\mathrm{TD}$, thermal desorption; TDU, thermal desorption unit; VOC, volatile organic compound; VVOC, very volatile organic compound

\section{REFERENCES}

(1) Hahladakis, J. N., Velis, C. A., Weber, R., Iacovidou, E., and Purnell, P. (2018) An overview of chemical additives present in plastics: Migration, release, fate and environmental impact during their use, disposal and recycling. J. Hazard. Mater. 344, 179-199.

(2) Zhao, Q., Li, Y., Chai, X., Xu, L., Zhang, L., Ning, P., Huang, J., and Tian, S. (2019) Interaction of inhalable volatile organic compounds and pulmonary surfactant: Potential hazards of VOCs exposure to lung. J. Hazard. Mater. 369, 512-520.

(3) Carratt, S. A., Morin, D., Buckpitt, A. R., Edwards, P. C., and Van Winkle, L. S. (2016) Naphthalene cytotoxicity in microsomal epoxide hydrolase deficient mice. Toxicol. Lett. 246, 35-41.

(4) Lehmann, R., Schobel, N., Hatt, H., and van Thriel, C. (2016) The involvement of TRP channels in sensory irritation: a mechanistic approach toward a better understanding of the biological effects of local irritants. Arch. Toxicol. 90 (6), 1399-413.

(5) Masuck, I., Hutzler, C., and Luch, A. (2010) Investigations on the emission of fragrance allergens from scented toys by means of headspace solid-phase microextraction gas chromatography-mass spectrometry. J. Chromatogr A 1217 (18), 3136-43.

(6) Marc, M., Formela, K., Klein, M., Namiesnik, J., and Zabiegala, B. (2015) The emissions of monoaromatic hydrocarbons from small polymeric toys placed in chocolate food products. Sci. Total Environ. 530-531, 290-296.

(7) Tirendi, S., Geiss, O., Barrero-Moreno, J., and Kotzias, D. (2009) Chemical emissions from toys - the case of stink blasters. Int. J. Environ. Anal. Chem. 89 (8-12), 929-938.

(8) Masuck, I., Hutzler, C., Jann, O., and Luch, A. (2011) Inhalation exposure of children to fragrances present in scented toys. Indoor Air 21 (6), 501-11.

(9) Analysis and Risk Assessment of Fragrances and Other Organic Substances in Squishy Toys; Danish EPA: August 2018.

(10) Even, M., Girard, M., Rich, A., Hutzler, C., and Luch, A. (2019) Emissions of VOCs From Polymer-Based Consumer Products: From Emission Data of Real Samples to the Assessment of Inhalation Exposure. Front. Public Health 7, 202.

(11) Bild. Merkel ist giftiger als Stoiber. https://www.bild.de/news/ 2007/tuev-bams-test-1355414.bild.html [in German] (accessed 202012-14).

(12) BVL. Karnevalsartikel vor dem Kauf ausprobieren. https://www. bvl.bund.de/SharedDocs/Pressemitteilungen / 03 verbraucherprodukte/2013/2013_01_31_pi_karneval.html [in German] (accessed 2020-12-14).

(13) Denk, P., Velasco-Schon, C., and Buettner, A. (2017) Resolving the chemical structures of off-odorants and potentially harmful substances in toys-example of children's swords. Anal. Bioanal. Chem. 409 (22), 5249-5258.

(14) Wiedmer, C., Velasco-Schon, C., and Buettner, A. (2017) Characterization of off-odours and potentially harmful substances in a fancy dress accessory handbag for children. Sci. Rep. 7 (1), 1807.
(15) Wiedmer, C., and Buettner, A. (2018) Quantification of organic solvents in aquatic toys and swimming learning devices and evaluation of their influence on the smell properties of the corresponding products. Anal. Bioanal. Chem. 410 (10), 2585-2595.

(16) Wiedmer, C., and Buettner, A. (2019) Identification and characterisation of odorants in a squishy toy using gas chromatography-mass spectrometry/olfactometry after thermal extraction. Anal. Bioanal. Chem. 411 (17), 3757-3761.

(17) Wargocki, P. N. K. H., and Zuczek, P. (2007) Effect of Using Low-Polluting Building Materials and Increasing Ventilation on Perceived Indoor Air Quality, In CLIMA 2007. WellBeing Indoors. Proceedings of the 9th REHVA World Congress, Helsinki, Finland, FINVAC, Helsinki, Finland.

(18) Han, K. H., Zhang, J. S., Wargocki, P., Knudsen, H. N., and Guo, B. (2010) Determination of material emission signatures by PTR-MS and their correlations with odor assessments by human subjects. Indoor Air 20 (4), 341-54.

(19) Kim, K. H., Kim, S. H., Jung, Y. R., and Kim, M. G. (2008) Evaluation of malodor for automobile air conditioner evaporator by using laboratory-scale test cooling bench. J. Chromatogr A 1204 (1), $72-80$.

(20) Gonzalez, D., Colon, J., Sanchez, A., and Gabriel, D. (2019) A systematic study on the VOCs characterization and odour emissions in a full-scale sewage sludge composting plant. J. Hazard. Mater. 373, $733-740$.

(21) Rozzi, T., Snyder, J., and Novak, D. (2012) Pilot study of aromatic hydrocarbon adsorption characteristics of disposable filtering facepiece respirators that contain activated carbon. J. Occup. Environ. Hyg. 9 (11), 624-9.

(22) Gupta, J. K., Lin, C. H., and Chen, Q. (2010) Characterizing exhaled airflow from breathing and talking. Indoor Air 20 (1), 31-9.

(23) ISO (2011) ISO 16000-6:2011. Indoor Air Part 6 Determination of Volatile Organic Compounds in Indoor and Test Chamber Air by Active Sampling on Tenax TA® Sorbent, Thermal Desorption, and Gas Chromatography Using MS or MS-FID, ISO.

(24) ECHA Derived No-Effect Levels from the European Chemicals Agency. https://echa.europa.eu/ (accessed 2020-12-14).

(25) Agreed EU-LCI Values (December 2019)_Substances with Their Established EU-LCI Values and Summary Fact Sheets. https://ec. europa.eu/docsroom/documents/39985 (accessed 2020-12-14).

(26) AgBB-Evaluation Procedure for VOC Emissions from Building Products. 2018. https://www.umweltbundesamt.de/sites/default/ files/medien/355/dokumente/agbb_evaluation_scheme_2018.pdf (accessed 2020-12-14).

(27) ECHA Guidance on Information Requirements and Chemical Safety Assessment. Chapter R.8: Characterisation of Dose [Concentration]-Response for Human Health. 2012. https://echa.europa.eu/ documents/10162/13632/information_requirements_r8_en.pdf (accessed 2020-12-14).

(28) European Collaborative Action: Urban Air, Indoor Environment and Human Exposure (2013) Report No 29: Harmonisation Framework for Health Based Evaluation of Indoor Air Emissions from Construction Products in the European Union Using the EU-LCI Concept, EUR $26168 \mathrm{EN}$, European Union.

(29) Trivedi, D. K., Sinclair, E., Xu, Y., Sarkar, D., Walton-Doyle, C., Liscio, C., Banks, P., Milne, J., Silverdale, M., Kunath, T., Goodacre, R, and Barran, P. (2019) Discovery of Volatile Biomarkers of Parkinson's Disease from Sebum. ACS Cent. Sci. 5 (4), 599-606.

(30) van Den Dool, H., and Dec. Kratz, P. (1963) A generalization of the retention index system including linear temperature programmed gas-liquid partition chromatography. J. Chromatogr. A $11,463-471$.

(31) Bradtmiller, B., and Friess, M. A Head-and-Face Anthropometric Survey of U.S. Respirator Users. 2004. https://www.nap.edu/resource/ 11815/Anthrotech_report.pdf (accessed 2020-12-14).

(32) Tsuge, S., Ōhtani, H., and Watanabe, C. Pyrolysis-GC/MS Data Book of Synthetic Polymers - Pyrograms, Thermograms and MS of Pyrolyzates; Elsevier: Oxford, 2011. 
(33) Niaz, K., Bahadar, H., Maqbool, F., and Abdollahi, M. (2015) A review of environmental and occupational exposure to xylene and its health concerns. EXCLI J. 14, 1167-86.

(34) ECHA. Naphthalene - Substance Information. https://echa. europa.eu/de/substance-information/-/substanceinfo/100.001.863 (accessed 2020-12-14).

(35) Woelk, H. J., and Mestl, G. (2012) Catalyst optimization strategy: selective oxidation of o-xylene to phthalic anhydride. Comb. Chem. High Throughput Screening 15 (2), 136-9.

(36) Sanmarin, O., and de la Cuadra, J. (1992) Occupational contact dermatitis from cyclohexanone as a PVC adhesive. Contact Dermatitis 27 (3), 189-190.

(37) Lim, C. H., Lee, Y. H., Kim, Y. S., Choi, H. S., and Seo, D. S. (2018) Assessment of cyclohexanone toxicity in inhalation-exposed F344 rats and $\mathrm{B} 6 \mathrm{C} 3 \mathrm{~F} 1$ mice: applications in occupational health. Inhalation Toxicol. 30 (7-8), 247-254.

(38) Even, M., Hutzler, C., Wilke, O., and Luch, A. (2020) Emissions of volatile organic compounds from polymer-based consumer products: Comparison of three emission chamber sizes. Indoor Air 30 (1), 40-48.

(39) Li, W., Belmont, B., Greve, J. M., Manders, A. B., Downey, B. C., Zhang, X., Xu, Z., Guo, D., and Shih, A. (2016) Polyvinyl chloride as a multimodal tissue-mimicking material with tuned mechanical and medical imaging properties. Med. Phys. 43 (10), 5577.

(40) Pirow, R., Blume, A., Hellwig, N., Herzler, M., Huhse, B., Hutzler, C., Pfaff, K., Thierse, H. J., Tralau, T., Vieth, B., and Luch, A. (2019) Mineral oil in food, cosmetic products, and in products regulated by other legislations. Crit. Rev. Toxicol. 49 (9), 742-789.

(41) ECHA. Guidance on Information Requirements and Chemical Safety Assessment Chapter R.15: Consumer Exposure Assessment. 2016. https://echa.europa.eu/documents/10162/13632/information requirements_r15_en.pdf/35e6f804-c84d-4962-acc5-6546dc5d9a55 (accessed 2020-12-14).

(42) Scientific Committee on Health, Environmental and Emerging Risks (SCHEER). Request for an Opinion on Toxicological Reference Values for Certain Organic Chemicals Emitted from Squishy Toys with Regard to Adopting Limit Values under the Toy Safety Directive 2009/ 48/EC. https://ec.europa.eu/health/sites/health/files/scientific committees/scheer/docs/scheer_q_017.pdf (accessed 2020-12-14).

(43) (2017) DIN EN 16516:2017. Construction Products - Assessment of Release of Dangerous Substances - Determination of Emissions into Indoor Air, European Committee for Standardization.

(44) Fent, K. W., Evans, D. E., Booher, D., Pleil, J. D., Stiegel, M. A., Horn, G. P., and Dalton, J. (2015) Volatile Organic Compounds Offgassing from Firefighters' Personal Protective Equipment Ensembles after Use. J. Occup. Environ. Hyg. 12 (6), 404-14. 